\title{
Relationship between the paraoxonase (PON1) L55M and Q192R polymorphisms and obesity in a Mexican population: a pilot study
}

\author{
Maria Fernanda Martínez-Salazar • Damianys Almenares-López • \\ Sara García-Jiménez • Miguel Angel Sánchez-Alemán • Alina Juantorena-Ugás • \\ Camilo Ríos · Antonio Monroy-Noyola
}

Received: 16 November 2010/Accepted: 8 March 2011/Published online: 25 March 2011

(c) Springer-Verlag 2011

\begin{abstract}
The aim of this study was to examine the relationship between the L55M and Q192R paraoxonase (PON1) polymorphisms and obesity in a population of adult Mexican workers. The study population included 127 adult individuals from the Universidad Autónoma del Estado de Morelos, ranging in age from 20 to 56 years and representing both sexes. Based on body mass index, 63 individuals were classified as obese and 64 as normal weight. The PON1-Q192R and PON1-L55M polymorphisms were determined by restriction fragment length polymorphism PCR analysis. Both arylesterase and paraoxonase activity
\end{abstract}

This work was supported and financed by PROMEP/SEP/103.5/07/ 1737 and CONACYT 106436.

M. F. Martínez-Salazar

Laboratorio de Diagnóstico Molecular, Facultad de Farmacia,

Universidad Autónoma del Estado de Morelos,

Av. Universidad 1001 Col. Chamilpa,

62209 Cuernavaca, Morelos, México

D. Almenares-López · S. García-Jiménez ·

A. Juantorena-Ugás · A. Monroy-Noyola ( $\square)$

Laboratorio de Neuroprotección y Bioquímica Clínica,

Facultad de Farmacia, Universidad Autónoma del Estado de

Morelos, Av. Universidad 1001 Col. Chamilpa,

62209 Cuernavaca, Morelos, México

e-mail: amonroy@uaem.mx

\section{A. Sánchez-Alemán}

Centro de Investigaciones sobre Enfermedades Infecciosas, Instituto Nacional de Salud Pública, Av. Universidad 655,

62100 Cuernavaca, Morelos, México

\section{Ríos}

Departamento de Neuroquímica, Instituto Nacional de Neurología y Neurocirugía, "Manuel Velasco Suárez", SS, Av. Insurgentes Sur No. 3877, 14269 Distrito Federal, México levels were similar in both groups, whereas systolic pressure, triglyceride, total cholesterol, low-density lipoprotein cholesterol, very-low-density lipoprotein cholesterol, glucose, and insulin levels were higher in the obese group than in the normal-weight group $(P<0.05)$. An exception was the high-density lipoprotein cholesterol (HDL-C) levels, which were lower in the obese group $(P<0.05)$. Although the PON1-Q192R polymorphism was not associated with either group, the frequency of the homozygous L genotype for the PON1-L55M polymorphism was higher in the obese group than in the normal-weight group $(P<0.05)$. In conclusion, this study established a positive association between the PON1-L55M homozygous L genotype and obesity.

Keywords Paraoxonase - PON1 - Obesity ·

Human · Polymorphism

\section{Introduction}

An increase in oxidative stress has been suggested to be a consequence of obesity in humans, which contributes to the development of comorbidities such as diabetes mellitus, hypertension, atherosclerosis, chronic renal failure, dyslipidemia, cancer, and coronary heart disease (CHD) [18, 38]. High-density lipoprotein cholesterol (HDL-C) has antioxidant properties and the capacity to inhibit the oxidative modification of low-density lipoprotein cholesterol (LDL-C) [26]. HDL-C is coupled to proteins with antioxidant activity, such as paraoxonase 1 (PON1). This enzyme is involved in the metabolism of lipoprotein phospholipids and inhibits lipid peroxidation of LDL-C [9].

PON1, an esterase that was initially characterized by its ability to hydrolyze organophosphate compounds including 
the insecticide paraoxon [9], is involved in the metabolism of lipoprotein phospholipids and inhibits lipid peroxidation of LDL-C [25]. The enzyme is synthesized mainly in the liver, but some is secreted into the bloodstream, where it associates with HDL-C [8]. Recently, PON1 has been found in the interstitial space between unilocular cells (white fat cells) of the adipose tissue [29]. The PON1 gene contains two polymorphisms within its coding region: a leucine (L) to methionine (M) substitution at position 55 (L55M) and a glutamine $(\mathrm{Q})$ to arginine $(\mathrm{R})$ substitution at position 192 (Q192R) [1]. The Q192R polymorphism seems to be the major determinant of serum PON1 activity on various organophosphate compounds [7], and these polymorphisms has also been reported to affect the in vivo ability of the enzyme to hydrolyze oxidized lipids [27]. Although the L55M polymorphism does not affect the catalytic activity on different organophosphate compounds, the $\mathrm{M}$ allele has been correlated with decreased mRNA and protein levels [23].

It has been reported that oxidized low-density lipoprotein (oxLDL) can be internalized by the adipocyte, which contributes to its proliferation by increasing the adipose tissue mass [28]. Hence, we hypothesized that PON1 polymorphisms with low antioxidant capacity may be associated with obese subjects.

Currently, only a few studies examined the correlation between obesity and PON1. Ferretti et al. [11] demonstrated that there is increased oxidation of LDL-C and HDL-C, and low levels of paraoxonase activity in obese subjects compared with healthy individuals. The protective role of PON1 in obesity is also supported by an observed increase in paraoxonase activity and a decrease in body mass index (BMI) in obese patients who were prescribed orlistat (a drug designed to treat obesity) in addition to a reduced-calorie diet [2]. Another study reported that there are changes in the lactonase activity of PON1 in overweight and obese women after a reduced-calorie dietary plan, which is reflected in a reduction in BMI and a significant reduction in LDL-C levels [20]. In contrast, Tabur et al. [37] found no change in either arylestarase or paraoxonase activity in obesity and non-diabetic metabolic syndrome, although oxidative stress and the inflammatory process were affected.

Studies examining PON1 and obesity have mainly focused on determining the paraoxonase/arylestarase/lactonase activity levels in obesity. As mentioned earlier, the enzymatic activity of PON1 is strongly determined by its genotype. Thus, the aim of this study was to examine the relationship between obesity and the Q192R and L55M polymorphisms in an adult population of workers from the Universidad Autónoma del Estado de Morelos (UAEM) and their relationship to the levels of paraoxonase and arylesterase activity.

\section{Methods and procedures}

Population study

From October 2007 to April 2008, a request to participate in a study called "Biochemical and molecular characterization of obesity in workers" from the Universidad Autónoma del Estado de Morelos was issued (unpublished data). All participants signed a letter of informed consent and answered a questionnaire that was used to obtain sociodemographic information, alimentary habits, and lifestyle details such as diet, smoking, and alcohol consumption, as well as determine their risk factors for diabetes, cardiovascular disease, and hypertension. Each worker was weighed without shoes and in light clothing using scales that had been previously calibrated to an accuracy of $\pm 0.5 \mathrm{~kg}$. Height was measured in meters using a stadimeter, measuring the participant without shoes, erect, and with back to a flat surface. Both measurements were performed by trained personnel and standardized by the Habicht [16] technique to avoid observational bias. After a rest of at least $5 \mathrm{~min}$, during which the participant was sitting back in a chair, blood pressure (BP) was measured in a quiet environment using a Citizen ${ }^{\mathrm{TM}}$ digital oscillometric tensiometer (Citizen Watch Co., Ltd., Tokyo, Japan, model no. CH-432B) on the right arm. After the anthropometric and BP measurements were taken, two 10-ml samples of venous blood were obtained in clean, nonheparinized vials from each participant, after a 10-h fasting period, for biochemical and molecular analyses.

The BMI was calculated for each worker [39], and individuals were classified into 4 groups: underweight (BMI $<18.5$ ), normal weight $(\mathrm{BMI}=18.5-24.9)$, overweight $(\mathrm{BMI}=25.0-29.9)$, and obese (BMI $>30.0)$.

The sample size was calculated by taking the allelic frequencies for the PON1-L55M previously reported by Rojas-García et al. [32] for a Mexican population. Thus, consecutive samples were obtained from 64 normal-weight individuals and 63 obese individuals. This study was approved by the ethics committee of the National Institute of Neurology and Neurosurgery (INNN), Ministry of Health.

\section{Biochemical analyses}

TC, TG, HDL-C, and LDL-C were measured with a Hitachi 912 autoanalyzer (Roche, Basel, Switzerland) using the enzymatic colorimetric test CHOD-PAP (catalog no. 1489232, Roche Diagnostic), the homogenous enzymatic colorimetric test LDL-C plus 2nd generation (catalog no. 04714423190, Roche Diagnostic), the HDL-C plus 3rd generation test (catalog no. 04713109 190, Roche Diagnostic), and the enzymatic colorimetric test GPO-PAP (catalog no. 1488872, Roche Diagnostic), respectively. 
Insulin levels were determined by an electrochemiluminescent immunoassay (catalog no. 03184897, Roche Diagnostic).

\section{Paraoxonase activity}

The paraoxonase activity of PON1 was measured by monitoring the hydrolysis of paraoxon into p-nitrophenol and diethylphosphate. The initial velocity of p-nitrophenol production at $37^{\circ} \mathrm{C}$ was followed by spectrophotometry at a 412-nm wavelength (UV/VIS-Varian Cary 50, Varian Inc., Palo Alto, CA), correcting for spontaneous paraoxon hydrolysis. Serum was added to the assay mixture to reach a final concentration of $1 \mathrm{mM}$ paraoxon, $2.5 \mathrm{mM} \mathrm{CaCl}_{2}$, $10 \mathrm{mM}$ Tris- $\mathrm{HCl}(\mathrm{pH} \mathrm{8})$, and $2.6 \mathrm{M} \mathrm{NaCl}$ [19].

\section{Arylesterase activity}

The arylesterase activity of PON1 was determined using phenyl acetate as a substrate as previously described [15]. The initial rate of phenyl acetate hydrolysis in serum was measured in a cuvette containing a solution of $1 \mathrm{mM}$ phenyl acetate, $2.5 \mathrm{mM} \mathrm{CaCl}_{2}$, and $10 \mathrm{mM}$ Tris- $\mathrm{HCl}(\mathrm{pH}$ $8.0)$ at $25^{\circ} \mathrm{C}$. The basal level of spontaneous hydrolysis was determined by running a blank sample without serum, and this value was subtracted from all experimental values to obtain a true measurement of enzymatic hydrolysis. Phenyl acetate hydrolysis was monitored by spectrophotometry at a 270-nm wavelength. The reaction mixture solution was prepared fresh on a daily basis before the experiments. One unit of arylesterase activity per milliliter is equivalent to the hydrolysis of one micromole of phenyl acetate per minute.

\section{Determination of the PON1-Q192R and PON1-L55M} genotypes

Genomic DNA was extracted from heparinized peripheral blood using the Aquapure ${ }^{\mathrm{TM}}$ Genomic DNA kit (cat. no. 732-63459; Bio-rad Laboratories, Hercules, CA). PCR was performed according to previously published protocol [19]. The primer sequences for PON1-Q192R were the follow-

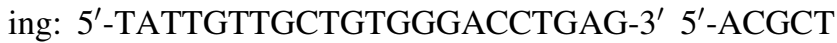
AAACCCAAATACATCTC- $3^{\prime}$. The primer sequences for PON1-L55M were the following: 5'-GAAGAGTGATGT ATAGCCCCAG-3' 5'-TTTAATCCAGAGCTAATGAA A GCC- $3^{\prime}$.

The 25- $\mu \mathrm{l}$ reaction consisted of $15 \mathrm{pmol}$ of each primer, $100 \mathrm{ng}$ of DNA template, $1 \times$ Taq Buffer $\left(\left[\mathrm{NH}_{4}\right]_{2} \mathrm{SO}_{4}\right)$, $200 \mathrm{mM}$ dNTPs, $1.25 \mathrm{mM} \mathrm{MgCl} 2,1 \mathrm{U}$ of Taq DNA polymerase, and sterile $\mathrm{dH}_{2} \mathrm{O}$. The amplification program included an initial denaturation step at $92^{\circ} \mathrm{C}$ for $5 \mathrm{~min}$, followed by 35 cycles of denaturation at $92^{\circ} \mathrm{C}$ for $30 \mathrm{~s}$, annealing at $60^{\circ} \mathrm{C}$ for $30 \mathrm{~s}$, extension at $72^{\circ} \mathrm{C}$ for $30 \mathrm{~s}$, and a final extension at $72^{\circ} \mathrm{C}$ for $10 \mathrm{~min}$.

Single-nucleotide polymorphism (SNP) detection was based on restriction fragment length polymorphism (RFLP) analysis after PCR amplification. The PCR products were digested at $55^{\circ} \mathrm{C}$ for $1 \mathrm{~h}$ using BspPI (catalog no. ER1321, Fermentas) for PON1-Q192R and at $37^{\circ} \mathrm{C}$ for $1 \mathrm{~h}$ using Hin1II (catalog no. ER1831, Fermentas) for PON1-L55M. The digested fragments were separated by electrophoresis in 7.5 and $20 \%$ polyacrylamide gels for PON1-L55M and PON1-Q192R, respectively.

All sample genotyping was carried out by laboratory personnel in a blind test, which included quality control samples with the experimental samples for validation. The concordance with the quality control samples was $100 \%$.

Statistical analysis

The questionnaire data and the results from the biochemical and molecular assays were entered into a database and subsequently analyzed using the Statistical Package for the Social Sciences (SPSS) software version 16.0 for Windows $^{\mathrm{TM}}$ (SPSS Inc. Chicago, IL).

For categorical variables, the $\chi^{2}$ test was used to compare the normal-weight and obese subjects two by two, and crude prevalence ratios were calculated with a $95 \%$ confidence interval. For continuous variables, the Student's $t$ test and Mann-Whitney U test were used as appropriate, based on the normality of the variables (KolmogorovSmirnov test). Only those variables having statistical significance $(P<0.05)$ after these comparisons were included in a logistic regression model. The odds ratios derived from a logistic regression analysis were adjusted for possible confounding factors.

The existence of Hardy-Weinberg equilibrium was confirmed $(P=0.086$ and 0.949 for PON1-L55M and PON1-Q192R, respectively).

\section{Results}

Blood biochemical data, PON1 genotypes, and alleles frequencies

The normal-weight individuals were younger than the obese individuals (Table 1). The systolic and diastolic BP, glucose, TG, TC, LDL-C, VLDL-C, and insulin levels were significantly higher in the obese group than in the normal-weight group $(P<0.05)$. HDL-C levels, however, were significantly higher in the normal-weight group $(P=0.001)$ (Table 1$)$. There were no differences in the paraoxonase and arylesterase activities between the two study groups. 
Table 1 General characteristics, biochemical laboratory data, genotypes, and alleles frequencies

\begin{tabular}{|c|c|c|c|}
\hline & $\begin{array}{l}\text { Normal weight } \\
\text { Media }(95 \% \mathrm{CI})\end{array}$ & $\begin{array}{l}\text { Obese subject } \\
\text { Media }(95 \% \mathrm{CI})\end{array}$ & $\begin{array}{l}P \text { value }^{\mathrm{a}} \\
\text { (obese vs. } \\
\text { normal weight) }\end{array}$ \\
\hline Age (years) & $39(36.7-41.1)$ & $43(40.7-45.8)$ & 0.018 \\
\hline \multicolumn{4}{|l|}{$\operatorname{Sex}$} \\
\hline M & 14 & 19 & \multirow[t]{2}{*}{$0.194^{\mathrm{b}}$} \\
\hline $\mathrm{F}$ & 50 & 44 & \\
\hline BMI $\left(\mathrm{kg} / \mathrm{m}^{2}\right)$ & 23 & 33 & $<0.001$ \\
\hline Systolic (mm Hg) & $115(110.6-118.9)$ & $127(121.5-131.9)$ & $<0.001$ \\
\hline Diastolic (mm Hg) & $71(68.5-73.3)$ & $76(72.8-79.0)$ & 0.012 \\
\hline Glucose (mg/dl) & $73(71.0-75.9)$ & $85(76.7-92.4)$ & 0.012 \\
\hline TG (mg/dl) & $112(95.7-127.9)$ & $168(146.7-189.5)$ & $<0.001$ \\
\hline $\mathrm{TC}(\mathrm{mg} / \mathrm{dl})$ & $177(169.6-184.7)$ & 199 (190.9-206.4) & $<0.001$ \\
\hline HDL-C (mg/dl) & $50(46.6-52.5)$ & $43(40.2-45.0)$ & $<0.001$ \\
\hline LDL-C (mg/dl) & $109(102.1-114.8)$ & $128(121.7-134.0)$ & $<0.001$ \\
\hline VLDL-C (mg/dl) & $23(29.9-26.1)$ & $31(28.1-34.6)$ & $<0.001$ \\
\hline Insulin (mg/dl) & $8(6.9-8.6)$ & $17(14.7-18.9)$ & $<0.001$ \\
\hline Paraoxonase activity (nmol/min/ml) & $177(137.0-217.8)$ & $172(122.3-221.3)$ & 0.858 \\
\hline \multirow[t]{2}{*}{ Arylesterase activity $(\mu \mathrm{mol} / \mathrm{min} / \mathrm{ml})$} & $70(49.3-90.0)$ & $71.0(47.8-94.8)$ & 0.964 \\
\hline & Frequency $(\%)$ & \multicolumn{2}{|l|}{ Frequency $(\%)$} \\
\hline \multicolumn{4}{|l|}{ PON1-L55M genotype } \\
\hline $\mathrm{LL}$ & 65.6 & 81 & \multirow[t]{3}{*}{$0.032^{\mathrm{b}}$} \\
\hline LM & 26.6 & 19 & \\
\hline MM & 7.8 & 0 & \\
\hline Allele L frequency & 78.9 & 90.5 & \multirow[t]{2}{*}{$0.0075^{\mathrm{b}}$} \\
\hline Allele $\mathrm{M}$ frequency & 20.8 & 9.5 & \\
\hline \multicolumn{4}{|l|}{ PON1-Q192R genotype } \\
\hline QQ & 31.3 & 28.6 & \multirow[t]{3}{*}{$0.944^{\mathrm{b}}$} \\
\hline QR & 35.9 & 38.1 & \\
\hline $\mathrm{RR}$ & 32.8 & 33.1 & \\
\hline Allele Q frequency & 49.2 & 47.6 & \multirow[t]{2}{*}{$0.989^{\mathrm{b}}$} \\
\hline Allele R frequency & 50.7 & 52.4 & \\
\hline
\end{tabular}

$P<0.05$ statistical significance

BMI body mass index, $T G$ triglycerides, $T C$ total cholesterol, $H D L-C$ high-density lipoprotein cholesterol, $L D L-C$ low-density lipoprotein cholesterol, $V L D L-C$ very-low-density lipoprotein cholesterol

a Independent samples $t$ test

b Chi square nonparametric test

An analysis of the genotype frequency in the whole population revealed that the most frequent genotype for PON1-L55M was LL (73.2\%), while the least common genotype was MM (3.9\%). The $\mathrm{L}$ and $\mathrm{M}$ allele frequencies were 84.6 and $15.4 \%$, respectively. For PON1-Q192R, the genotype frequencies were very similar, with $\mathrm{QR}$ being slightly more common (37\%) than QQ (29.9\%) (data not shown). The $\mathrm{Q}$ and $\mathrm{R}$ allele frequencies were 48.4 and $51.6 \%$, respectively. These results are similar to those reported by Rojas-García et al. [32] for the general Mexican population.
Table 1 shows the distribution of the PON1-L55M and PON1-Q192R genotypes and alleles frequencies for both groups. In the obese group, 51 individuals had the LL genotype, 12 individuals had the LM genotype, and no individuals had the MM genotype. This distribution differed significantly $(P=0.032)$ from that of the normalweight group. The frequency of the $\mathrm{L}$ allele in the obese group was higher than that in the normal-weight group $(P=0.0075$; Table 1).

A comparison of (LL) versus (LM $+\mathrm{MM})$ yielded a crude odds ratio of 2.226. A similar magnitude for the LL 
Table 2 Logistic regression analysis of genotypes PON1-L55M (LL) and (LM + MM) and PON1-Q192R (QQ) and (QR + RR) in obese and normal-weight subjects

\begin{tabular}{lllll}
\hline Polymorphism & LL $\%(n)$ & LM + MM \% (n) & Adjusted $P$ value $^{\mathrm{a}}$ & Adjusted OR $^{\mathrm{a}}$ \\
\hline Obese subjects & $81(51)$ & $19(12)$ & 0.032 & $2.7($ IC 95\% 1.1-6.6) \\
Normal weight & $65(42)$ & $35(22)$ & & \\
\hline QQ \% (n) & QR + RR \% (n) & 0.530 & 0.8 (IC 95\% 0.3-1.8) \\
\hline Obese subjects & $28.6(18)$ & $71.4(45)$ & & \\
Normal weight & $31(20)$ & $69(44)$ & & \\
\hline
\end{tabular}

${ }^{a} P$ and $\mathrm{OR}$ values obtained by the control of the confounding variable of age

genotype was obtained, after controlling for the confounding variable of age (Table 2). Furthermore, a multivariate logistic regression analysis was performed using a saturated model with the following variables: age, sex, birthplace, smoking habits, lipid-lowering medications, cardiovascular disease, diabetes mellitus, cholesterol, triglycerides, low-density lipoprotein, and high-density lipoprotein. The analysis gave an odds ratio of 3.6 (CI 95\% 1.3-10.1, $P=0.016)$. However, we considered the most parsimonious model to be relevant, and this model considered age as the biologically relevant characteristics.

Relationship between the PON1-L55M

and PON1-Q192R polymorphisms, enzyme

activities, and lipid profile

After grouping the paraoxonase activity values from both groups, QQ homozygous individuals for PON1-Q192R had an average value of $114.8 \mathrm{nmol} / \mathrm{min} / \mathrm{ml}$ (CI $95 \%=$ 78.7-150.9), QR heterozygous individuals had a mean value of $164.8 \mathrm{nmol} / \mathrm{min} / \mathrm{ml}($ CI 95\% = 109.1-220.5), and RR homozygous individuals had a mean value of
$242.8 \mathrm{nmol} / \mathrm{min} / \mathrm{ml}(\mathrm{CI} 95 \%=184.9-300.7)(P=0.002$; data not shown). As expected, the QQ, QR, and RR genotypes detected by PCR-RFLP correspond to low, intermediate, and high activity to degrade paraoxon, respectively. In addition, these differences are maintained when the paraoxonase activity values are analyzed in either the obese or normal-weight group alone (data not shown).

No statistically significant relation was found between the PON1-L55M alleles and arylesterase levels, although higher activity levels were detected in the LL individuals than in the LM + MM individuals (Table 3).

There was no statistically significant relationship between the means of the TG, TC, HDL-C, and LDL-C biochemical values and the PON1-L55M (LL) versus $(\mathrm{LM}+\mathrm{MM})$ or PON1-Q192R (QQ) versus (QR + RR) frequencies (Table 3).

\section{Discussion}

We used BMI, because it is the most commonly used adiposity index used for adults. BMI correlates significantly

Table 3 Relationship of the PON1-L55M and PON1-Q192R polymorphisms with the lipid profile of the normal-weight and obese groups

\begin{tabular}{|c|c|c|c|c|c|c|c|}
\hline & & \multicolumn{3}{|l|}{ PON1-192 } & \multicolumn{3}{|l|}{ PON1-55 } \\
\hline & & QQ (IC 95\%) & $\mathrm{QR}+\mathrm{RR}(\mathrm{IC} 95 \%)$ & $P$ value & LL (IC 95\%) & $\mathrm{LM}+\mathrm{MM}(\mathrm{IC} 95 \%)$ & $P$ value \\
\hline \multirow[t]{2}{*}{ TG (mg/dl) } & Normal weight & $115(90.1-147.4)$ & $111(78.3-129.4)$ & 0.725 & 105 (82.6-126.9) & $125(103.9-146.5)$ & 0.918 \\
\hline & Obese subjects & $162(88.1-211.4)$ & $171(139.8-191.1)$ & 0.823 & 169 (132.7-195.3) & $166(97-179.6)$ & 0.232 \\
\hline \multirow[t]{2}{*}{ TC (mg/dl) } & Normal weight & $177(157.7-191.1)$ & $177(167.1-190.5)$ & 0.933 & $174(164.9-182.7)$ & $184(168.7-198.2)$ & 0.662 \\
\hline & Obese subjects & 198 (182.7-219.6) & 199 (184.7-208.3) & 0.982 & $200(185-207.3)$ & 195 (181.2-225.7) & 0.230 \\
\hline \multirow[t]{2}{*}{ HDL (mg/dl) } & Normal weight & $52(44.8-58.4)$ & $44(39.8-48.2)$ & 0.254 & $51(46.9-54.5)$ & $48(40.7-58.5)$ & 0.364 \\
\hline & Obese subjects & $41(38.9-50.4)$ & $49(39.8-48.2)$ & 0.315 & $42(39.1-46.2)$ & $45(40.7-58.5)$ & 0.365 \\
\hline \multirow[t]{2}{*}{$\mathrm{LDL}(\mathrm{mg} / \mathrm{dl})$} & Normal weight & $107(73.8-163.7)$ & $109(100.1-121)$ & 0.639 & $105(97.1-113)$ & 115 (104.6-125.6) & 0.463 \\
\hline & Obese subjects & $130(121.8-145.5)$ & $127(117-136.4)$ & 0.820 & $129(119.2-137.7)$ & $123(115.0-143.0)$ & 0.130 \\
\hline \multirow{2}{*}{$\begin{array}{l}\text { Paraoxonase activity } \\
(\mathrm{nmol} / \mathrm{min} / \mathrm{ml})\end{array}$} & Normal weight & $119(73.8-163.7)$ & $211(155.0-267.2)$ & 0.024 & $202(144.1-259.2)$ & $135(87.0-183.5)$ & 0.091 \\
\hline & Obese subjects & $81(35-127.9)$ & $200(139.4-260.0)$ & 0.036 & $178(115.0-240.4)$ & $152(74.7-229.4)$ & 0.939 \\
\hline \multirow{2}{*}{$\begin{array}{l}\text { Arylesterase activity } \\
(\mathrm{nmol} / \mathrm{min} / \mathrm{ml})\end{array}$} & Normal weight & $81(44.8-117.6)$ & $64(39.0-88.2)$ & 0.392 & $74(47.8-100.8)$ & $63(30.8-95.7)$ & 0.594 \\
\hline & Obese subjects & $98(37.5-158.5)$ & 75 (47.6-101.9) & 0.391 & $85(56.4-113.7)$ & $67(11.8-121.1)$ & 0.531 \\
\hline
\end{tabular}

$T G$ triglycerides, $T C$ total cholesterol, $H D L-C$ high-density lipoprotein cholesterol, $L D L-C$ low-density lipoprotein cholesterol 
with body fat, morbidity, and mortality, and it can be calculated conveniently in a clinical setting. The last Mexican National Health and Nutrition Survey 2006 [4] used BMI to estimate the prevalence of overweight and obesity in Mexico. Furthermore, the US National Institute of Health recommendations for treatment of obesity are based on BMI [30]. We found that BMI was highly correlated with leptin concentration $(r=0.7)$, percentage body fat $(r=0.75)$, and waist circumference $(r=0.87$ ) in our population (data not show). These parameters are highly related to total adiposity $[10,36]$.

Our data indicate that obese subjects have a 2.7-fold increased chance of possessing the LL genotype of PON1L55M than do normal-weight individuals $(P=0.032)$. In contrast, no relationship was found between the PON1Q192R polymorphism and obesity $(P=0.944)$.

Interestingly, we found that normal-weight individuals who were homozygous for $\mathrm{M}$ allele were also homozygous for the Q allele. Mackness et al. [24] showed that QQ/MM genotype confers more protection against lipid peroxide production in LDLs than in RR/LL genotype. So, we hypothesize that PON1 from normal-weight subjects with homozygosity for $\mathrm{Q}$ and $\mathrm{M}$ alleles could regulate LDL lipid oxidation levels more efficiently. Hence, they have a lower risk of developing diseases associated with high oxidative stress. Thus, this may explain the reason behind the association of PON1-192R allele $[6,31]$ or PON1-55L allele [5] with CHD, a very frequent pathology in obesity.

Whether or not the PON1-L55M polymorphism is involved in the development of obesity remains to be established. Mature adipocytes have been reported to express the integral membrane protein CD36, which can recognize and bind oxidized LDL, leading to their internalization by the adipocytes [22]. Moreover, oxidized LDLs, when endocytosed by adipocytes, can stimulate adipocyte proliferation and differentiation, which then contributes to the modulation of adipose tissue mass [28]. We hypothesize that oxidized LDLs may encourage the development of obesity and that obesity can be largely avoided by the preventative action of PON1 due to its capacity to degrade oxidized LDLs in adipose tissue. The function of PON1 in adipose tissue, however, remains unknown. Thus, more studies are required to discern the quantity and the enzymatic activity against the oxidized LDLs in the adipose tissue and to determine whether PON1 plays an important role in adipocyte differentiation and proliferation.

The results obtained herein indicate that the PON1L55M and PON1-Q192R polymorphisms do not participate in the regulation of serum lipids (Table 3 ). These results agree with those from a study on a Mexican population by Gamboa et al. [14]. There are other studies, such as the one performed by Hegele et al. [17], that have reported a relationship between the PON1-Q192R polymorphism and serum lipids; these differences could be related to the type of population studied because those subjects likely possess lifestyle, dietary, and genetic characteristics that are different from those of the Mexican population.

Considering that the PON1-Q192R polymorphism is the main determinant of serum paraoxonase activity [7] and that its level can vary 10- to 40-fold in human serum [13], the similar paraoxonase activity values found in the normal-weight and obese subjects could be accounted for by the similar PON1-Q192R genotype frequencies found in both populations $(P=0.944$, Table 1$)$ and by the great variability of the enzyme activity seen in human serum in general.

Similar results for paraoxonase and arylestarase activities were obtained by Tabur et al. [37] when normal-weight and obese subjects were compared. These results contrast with studies by Ferretti et al. [11, 12] on an obese adult female population and by Koncsos et al. [21] on an obese child population, both of which found lower paraoxonase and arylesterase activity levels in the obese subjects. None of these other studies, however, determined the PON1 genotypes in their study populations.

There are other factors that could regulate the catalytic activity of the PON1 enzyme: age and overall way of life as well as nutritional, genetic, and pharmacological factors. There were no differences in these enzymatic activities when the whole study population was grouped by ages 21-40 years and $>41$ years $(P=0.760)$. In agreement, Saruhan et al. [34] reported that age did not affect PON1 serum activity levels. In contrast, Seres et al. [35], who worked with three groups with age differences of over 20 years, found age-associated differences in the enzymatic activity of PON1. To resolve these discrepancies, future studies should involve larger and more homogeneous populations.

The PON1 enzyme activity measurements in this study were performed with paraoxon and phenylacetate, exogenous substrates that are generally used for isoform ( $Q$ or $\mathrm{R}$ ) characterization. Therefore, the possibility that the mechanism of antioxidant action shown here may involve different sites in the catalytic center of PON1, which act on organophosphate compounds and aromatic esters, cannot be excluded. Such potential sites include residues Cys-284 [3] or His 115-His 134 [33].

In conclusion, the present study established a positive association between obesity and the PON1-L55M homozygous LL genotype. Further studies involving significantly larger populations, however, are required to confirm this association. Our study could have considerable interest for future in vivo and in vitro research to demonstrate the role that paraoxonase plays in the differentiation and proliferation of adipocytes, which could, in turn, contribute to the development of obesity. 
Acknowledgments We would like to thank Alejandra Terrazas Meraz and Ofmara Yadira Zúñiga Hernández for their help with the anthropometric measurements and results registry, $\mathrm{PhD}$ José Luis Montiel- Hernández for his comments on this article, and all participants in this study. This work was supported and financed by the PROMEP 103.5/07/1737 and CONACYT 106436.

Conflict of interest The authors declared no conflict of interest.

\section{References}

1. Adkins S, Gan KN, Mody M et al (1993) Molecular basis for the polymorphic forms of human serum paraoxonase/arylesterase: glutamine or arginine at position 191, for the respective A or B allozymes. Am J Hum Genet 52:598-608

2. Audikovszky M, Pados G, Seres I et al (2007) Orlistat increases serum paraoxonase activity in obese patients. Nutr Metab Cardiovasc Dis 17:268-273

3. Aviram M, Billecke S, Sorenson R et al (1998) Paraoxonase active site required for protection against LDL oxidation involves its free sulfhydryl group and is different from that required for its arylesterase/paraoxonase activities: selective action of human paraoxonase allozymes Q and R. Artherioscler Thromb Vasc Biol 18:1617-1624

4. Barquera S, Campos-Nonato I, Hernandez-Barrera L et al (2009) Obesity, central adiposity in Mexican adults: results from the Mexican national health, nutrition survey 2006. Salud Publica Mex 51(Suppl 4):S595-S603

5. Blatter Garin MC, James RW, Dussoix P et al (1997) Paraoxonase polymorphism Met-Leu54 is associated with modified serum concentrations of the enzyme. A possible link between the paraoxonase gene and increased risk of cardiovascular disease in diabetes. J Clin Invest 99:62-66

6. Christiansen L, Bathum L, Frederiksen H et al (2004) Paraoxonase1 polymorphisms and survival. Eur J Hum Genet 12:843847

7. Costa LG, Li WF, Richter RJ, Shih DM et al (1999) The role of paraoxonase (PON1) in the detoxication of organophosphates and its human polymorphism. Chem Biol Interact 119-120:429-438

8. Costa LG, Vitalone A, Cole T et al (2005) Modulation of paraoxonase (PON1) activity. Biochem Pharm 69:541-550

9. Eckerson HW, Wyte CM, La Du BN (1983) The human serum paraoxonase/arylesterase polymorphism. Am J Hum Genet 35: $1126-1138$

10. Falaschetti E, Hingorani A, Jones A et al (2010) Adiposity and cardiovascular risk factors in a large contemporary population of pre-pubertal children. Eur Heart J 31:3063-3072

11. Ferretti G, Baccheti T, Moroni C et al (2005) Paraoxonase activity in high density lipoproteins: a comparison between healthy and obese females. J Clin Endocrinol Metab 90:17281733

12. Ferretti G, Bacchetti T, Masciangelo S et al (2010) HDL-paraoxonase and membrane lipid peroxidation: a comparison between healthy and obese subjects. Obesity 6:1079-1084

13. Furlong CE, Richter RJ, Seidel SL et al (1988) Role of genetic polimorphism of human plasma paraoxonase/arylesterase in hydrolisis of the insecticide metabolites chlorpyrofos oxon and paraoxon. Am J Hum Genet 43:230-238

14. Gamboa R, Zamora J, Rodríguez-Pérez JM et al (2006) Distribution of paraoxonase PON1 gene polymorphisms in Mexican populations. Its role in the lipid profile. Exp Mol Pathol 80:85-90

15. Gan KN, Smolen A, Eckerson HW et al (1991) Purification of human serum paraoxonase/arylesterase. Drug Metab Dispos 19:100-106
16. Habicht JP (1974) Estandarización de métodos epidemiológicos cuantitativos sobre el terreno (standardization of anthropometric methods in the field). PAHO Bull 76:375-384

17. Hegele RA, Brunt JH, Connelly PW (1995) A polymorphism of the paraoxonase gene associated with variation in plasma lipoproteins in a genetic isolate. Arterioscler Thromb Vasc Biol 15:89-95

18. Hubert HB, Feinleib M, McNamara PM et al (1983) Obesity as an independent risk factor for cardiovascular disease: a 26 years follow up participants in the Framinham heart study. Circulation 72:53-60

19. Humbert R, Adler DA, Disteche CM et al (1993) The molecular basis of the human serum paraoxonase activity polymorphism. Nat Genet 3:73-76

20. Kazuhiko K, Nakane K, Sano Y et al (2009) Changes on the physiological lactonase activity of serum paraoxonase 1 by a diet intervention for weight loss in healthy overweight and obese women. J Clin Biochem Nutr 45:329-334

21. Koncsos P, Seres I, Harangi M et al (2010) Human paraoxonase-1 activity in childhood obesity and its relation to leptin and adiponectin levels. Pediatr Res 67:309-313

22. Kuniyasu A, Hayashi S, Nakayama H (2002) Adipocytes recognize and degrade oxidized low density lipoprotein through CD36. Biochem Biophys Res Commun 295:319-323

23. Leviev I, Franco N, James RW (1997) Two alleles of the human paraoxonase gene produce different amounts of mRNA: an explanation for differences in serum concentrations of paraoxonase associated with the (Leu-Met54) polymorphism. Arterioscler Thromb Vasc Biol 17:2935-2939

24. Mackness B, Durrington P, Mackness M (1999) Polymorphisms of paraoxonase genes and low-density lipoprotein lipid peroxidation. Lancet 353:468-469

25. Mackness MI, Arrol S, Durrington PN (1991) Paraoxonase prevents accumulation of lipoperoxides in low density lipoprotein. FEBS Lett 286:152-154

26. Mackness MI, Durrington PN (1995) HDL: its enzymes and its potential to influence lipid peroxidation. Atherosclerosis 115:243-253

27. Mackness MI, Arrol S, Mackness B et al (1997) Alloenzymes of paraoxonase and effectiveness of high-density lipoproteins in protecting low-density lipoprotein against lipid peroxidation. Lancet 349:851-852

28. Marsella R, Vari R, D‘Archivio M et al (2006) Oxidised LDL modulate adipogenesis in 3T-L1 preadipocytes by affecting the balance between cell proliferation and differentiation. FEBS Lett 580:2421-2429

29. Marsillach J, Mackness B, Mackness M et al (2008) Immunohistochemical analysis of paraoxonases-1,2 and 3 expression in normal mouse tissues. Free Radic Biol Med 45:146-157

30. National Institutes of Health (2000) The practical guide identification, evaluation, and treatment of overweight and obesity in adults. http://www.nhlbi.nih.gov/guidelines/obesity/prctgd_c.pdf

31. Odawara M, Tachi Y, Yamashita K et al (1997) Paraoxonase polymorphism (Gln192-Arg) is associated with coronary heart disease in Japanese noninsulin-dependent diabetes mellitus. J Clin Endocrinol Metab 82:2257-2260

32. Rojas-García AE, Solís-Heredia MJ, Piña-Guzmán B et al (2005) Genetic polymorphisms and activity of PON1 in a Mexican population. Toxicol Appl Pharmacol 205:282-289

33. Rosenblat M, Gaidukov L, Khersonsky O et al (2006) The catalytic histidine dyad of HDL-associated serum paraoxonase 1 (PON1) is essential for PON1-mediated inhibition of LDL oxidation and for stimulation of macrophage cholesterol efflux. J Biol Chem 281:7657-7665

34. Saruhan E, Olgun A, Oztürk K et al (2007) Age-related paraoxonase activity changes in Turkish population. Ann NY Acad Sci 1100:218-222 
35. Seres I, Paragh G, Deschene E et al (2004) Study of factors influencing the decreased HDL associated PON1 activity with aging. Exp Gerontol 39:59-66

36. Sorensen TIA, Echwald SM, Holm J-C (1996) Leptin in obesity. Br Med J 313:953-954

37. Tabur S, Torun AN, Sabuncu T (2010) Non-diabetic metabolic syndrome and obesity do not affect serum paraoxonase and arylesterase activities but do affect oxidative stress and inflammation. Eur J Endocrinol 162:535-541
38. Vincent HK, Taylor AG (2006) Biomarkers and potencial mechanisms of obesity-induced oxidant stress in humans. Int $\mathrm{J}$ Obes 30:400-418

39. World Health Organization (1995) Physical status: the use and interpretation of anthropometry. Report of a WHO expert committee. World Health Organ Tech Rep Ser 854:1-452 